\title{
Neuroimaging features in neuro-gnathostomiasis and angiostrongyliasis
}

\author{
Viroj Wiwanitkit
}

Received: 23 December 2011/ Accepted: 13 January 2012/Published online: 24 January 2012

(C) Springer-Verlag 2012

\section{Sir,}

The recent publication on conflict neuroimaging features in neuro-gnathostomiasis and angiostrongyliasis is very interesting [1]. I would like to share idea on the summary "neuroimaging studies may be useful to differentiate gnathostomiasis and angiostrongyliasis particularly in patients with indistinct clinical presentations [1]". Indeed, the two diseases have several different clinical characteristics and should not be missed by the practitioners in the tropical endemic area. By nature, the worm that cause gnathostomiasis is a wandering organism and can cause the problem due to its migration while the worm that cause angiostrongyliasis is rather inert and mainly causes the increased intracranial pressure.
Focusing on the imaging study in this work, the first problem is the few subjects and there was no control of confounding factors (especially for previous occult neurological disorder). In addition, the grading and severity of the diseases are other factors that might affect the resulted imaging.

Conflict on interest The authors report no conflicts of interest.

\section{Reference}

1. Kanpittaya J, Sawanyawisuth K, Intapan PM, Khotsri P, Chotmongkol V, Maleewong W (2011) A comparative study of neuroimaging features between human neuro-gnathostomiasis and angiostrongyliasis. Neurol Sci Nov 29 [Epub ahead of print]

V. Wiwanitkit $(\bowtie)$

Wiwanitkit House, Bangkhae, Bangkok 10160, Thailand

e-mail:wviroj@yahoo.com

V. Wiwanitkit

Hainan Medical College, Haikou, China

V. Wiwanitkit

Joseph Ayo Babalola University, Ikeji-Arakeji, Nigeria 